\title{
USO DO FOGO NA AGRICULTURA: MEDIDAS PREVENTIVAS E QUEIMA CONTROLADA NO PROJETO DE DESENVOLVIMENTO SUSTENTÁVEL TERRA NOSSA, NOVO PROGRESSO, PARÁ
}

\author{
Juliana Andressa Costa dos Santos ${ }^{1}$; Daniela Pauletto²; Cléo Gomes da Mota ${ }^{3}$; Saulo Ubiratan Pinheiro \\ da Silva4; Gabriela de Cássia Santos do Nascimento5; Vanessa Sousa Gomes ${ }^{6 .}$ \\ 1 Universidade Federal do Oeste do Pará, Santarém, Pará, Brasil, julianaandressa.c.s@gmail.com \\ 2 Universidade Federal do Oeste do Pará, Santarém, Pará, Brasil, danielapauletto@hotmail.com \\ ${ }^{3}$ Instituto Social Ambiental Floranativa, Belém, Pará, Brasil, motacleo@hotmail.com \\ ${ }^{4}$ Engenheiro Florestal, Santarém, Pará, Brasil, saulostm@gmail.com \\ ${ }^{5}$ Prefeitura Municipal de Oriximiná, Oriximiná, Pará, Brasil, gabriela.cassia1@gmail.com \\ 6Engenheira Florestal, Santarém, Pará, Brasil, vanessa.eng@live.com
}

RESUMO: Nas últimas décadas a floresta amazônica vem sofrendo pressão de diversos setores com sua constante destruição, o que acaba ocasionando a busca por soluções para minimizar os impactos sofridos. O trabalho teve como objetivo geral caracterizar as principais técnicas utilizadas para uso do fogo na prática agrícola e a prevenção de queima controlada por agricultores familiares do município de Novo Progresso. A coleta de dados foi realizada através de uma entrevista semiestruturada com aplicação in loco. Constatou-se que 14\% dos entrevistados não fazem uso do fogo na agricultura enquanto que a grande maioria dos produtores utilizam o fogo. Quanto as palestras de prevenção e combate a incêndios florestais, ministrados pela brigada de incêndios da região, 77\% dos entrevistados participaram destas atividades, 18\% nunca participaram, e 5\% não foi possível adquirir dados a respeito do questionamento. Como medida de proteção ao fogo acidental, 95\% dos produtores entrevistados fazem o uso de aceiro e 5\% não adotam essa prática. A manutenção destes aceiros é feita com maquinas agrícolas por uma pequena parcela (10\%) enquanto que 45\% dos entrevistados fazem a limpeza manualmente e $45 \%$ não fazem nenhum tipo de manutenção. São necessários a presença e efetividade dos órgãos públicos da região, junto aos agricultores assentados, para a melhoria nas condições do uso do fogo nas práticas agrícolas.

PALAVRAS-CHAVE: Agricultura, Assentamento, Incêndios.

\section{USE OF FIRE IN AGRICULTURE: PREVENTIVE MEASURES AND CONTROLLED BURNING IN THE SUSTAINABLE DEVELOPMENT PROJECT TERRA NOSSA, NOVO PROGRESSO, PARÁ}

ABSTRACT: In the last decades the Amazon forest has been under pressure from several sectors with its constant destruction, which ends up causing the search for 
solutions to minimize the impacts suffered. The objective of this work was to characterize the main techniques used for the use of fire in agricultural practice and the prevention of burning controlled by family farmers in the municipality of Novo Progresso. Data collection was performed through a semi-structured interview with in loco application. It was found that $14 \%$ of those interviewed do not use fire in agriculture while most producers use fire. As for the fire prevention and firefighting lectures given by the region's fire brigade, $77 \%$ of those interviewed participated in these activities, 18\% never attended, and 5\% could not acquire data regarding the questioning. As a measure of accidental fire protection, 95\% of the interviewed producers use aceiro and $5 \%$ do not adopt this practice. The maintenance of these fireworks is done with agricultural machines for a small portion (10\%) while $45 \%$ of the interviewees do the cleaning manually and $45 \%$ does no maintenance. The presence and effectiveness of public agencies in the region, together with settled farmers, are necessary to improve the conditions of the use of fire in agricultural practices.

KEYWORDS: Agriculture, Burning, Infrastructure.

\section{USO DEL FUEGO EN LA AGRICULTURA: MEDIDAS PREVENTIVAS Y QUEMA CONTROLADA EN EL PROYECTO DE DESARROLLO SOSTENIBLE TERRA NOSSA, NOVO PROGRESSO, PARÁ}

RESUMEN: En las últimas décadas la selva amazónica viene sufriendo presión de diversos sectores con su constante destrucción, lo que acaba ocasionando la búsqueda de soluciones para minimizar los impactos sufridos. El trabajo tuvo como objetivo general caracterizar las principales técnicas utilizadas para el uso del fuego en la práctica agrícola y la prevención de quema controlada por agricultores familiares del municipio de Novo Progresso. La recolección de datos fue realizada a través de una entrevista semiestructurada con aplicación in loco. Se constató que el 14\% de los entrevistados no hacen uso del fuego en la agricultura mientras que la gran mayoría de los productores utilizan el fuego. En cuanto a las charlas de prevención y combate a incendios forestales, ministrados por la brigada de incendios de la región, el 77\% de los entrevistados participaron de estas actividades, el 18\% nunca participó, y el 5\% no fue posible adquirir datos sobre el cuestionamiento. Como medida de protección al fuego accidental, el 95\% de los productores entrevistados hacen el uso de acebo y el 5\% no adopta esa práctica. El mantenimiento de estos aceitos se realiza con maquinas agrícolas por una pequeña parcela (10\%) mientras que el $45 \%$ de los entrevistados hacen la limpieza manualmente y el $45 \%$ no hacen ningún tipo de mantenimiento. Se requiere la presencia y efectividad de los órganos públicos de la región, junto a los agricultores asentados, para la mejora en las condiciones del uso del fuego en las prácticas agrícolas.

PALABRAS CLAVE: Agricultura, Infraestructura, Quema. 
Estruturalmente, a Amazônia Legal teve como principal característica a grande concentração dos ativos fundiários, o que acabou resultando, historicamente, em privilégios e concessões a agropecuária de grande porte, segundo o Instituto de Pesquisa Econômica Aplicada (IPEA, 2013).

Porém, a agricultura no Brasil sofreu inúmeras modificações ao longo do tempo, no caso da agricultura familiar as mudanças surgiram gradativamente, principalmente no que diz respeito a incentivos e políticas públicas voltadas ao agricultor familiar (OLIVEIRA et al., 2004). Para Marschner e Vanderlinde (2015) um fator que contribuiu para essas mudanças foram as ONGs, pois as mesmas voltaram seu olhar para a parte da sociedade menos favorecida, o que fez com que houvesse mudanças no cenário político com relação a agricultura familiar.

Diante desse contexto, algumas alternativas surgiram para solucionar problemáticas fundiárias e ambientais, como os projetos de assentamento ambientalmente diferenciados, dos quais se destacam a categoria de Projeto de Desenvolvimento Sustentável (PDS) principalmente em virtude do estabelecimento da Reserva Legal coletiva, segundo o Instituto Nacional de Colonização e Reforma Agrária (INCRA, 2015). Um exemplo desta modalidade é o PDS Terra Nossa, localizado no município de Novo Progresso - PA, criado em 2006 com a previsão inicial de assentar 998 famílias enquadradas na política de reforma agrária, prescrito pelo INCRA (2015).

Ao se falar em agricultura familiar, é comum pensar em queima, de acordo com Junior, Murrieta e Adams (2008) a agricultura de corte e queima vem sendo praticada ao longo de muito tempo, e consequentemente acabou se tornando uma prática cultural. Em vista disso, de uma maneira simples e abrangente, a agricultura de corte é queima é definida como um sistema agrícola, no qual se abrem clareiras e/ou retirasse parte de florestas ou capoeiras, para que essas áreas venham a se tornar cultiváveis por um menor período de tempo que as 
destinadas ao pousio (PEDROSO JUNIOR; MURRIETA; ADAMS, 2008).

Para Sá et al. (2015) na agricultura amazônica a prática de corte e queima é frequentemente utilizada para o preparo da área com a finalidade de plantio, e por ser um método impactante para o meio ambiente, os autores destacam a necessidade de uma busca por alternativas viáveis a agricultura, que reduzam ou sanem a prática de corte e queima nas áreas rurais.

De modo que é possível perceber que existe um embate quando $\mathrm{O}$ assunto é queima em áreas destinado ao plantio, alguns autores seguem a linha de pensamento em que há um benefício agregado a área por essa prática, enquanto outros $\mathrm{O}$ contradizem, afirmando que não há benefícios gerados pela prática de corte e queima, destacam Pedroso Junior, Murrieta e Adams et al. (2008).

Dick et al. (2008) ressalta que a prática da queima é muito usual no meio rural, principalmente, ressalvam os autores, quando utilizada como medida eliminatória dos vegetais mortos "mantilho", e pelo fato de acreditarem que ocorre um aumento de nutrientes do solo após a queima.

Soares e Batista (2007) destacam que há uma relação entre o fogo e a silvicultura, porém acarreta em consequências, como os incêndios florestais. Mesmo que os produtores adotem práticas de proteção, é comum ocorrer o descontrole da queima e o fogo vir a danificar e muitas vezes destruir áreas cultivadas e extensões florestais.

Segundo Liesenfeld et al. (2016) o fogo não é apenas vilão, e pode ser utilizado de maneira variada e para diversas finalidades, como prevenção de incêndios, para a manutenção e construção de aceiros em áreas de plantio, queima de material enleirados e redução de material combustível, manejo de pastagens, da fauna silvestre e no controle de pragas e doenças, destacado também por Soares e Batista (2007).

Sá et al. (2015) no município de Novo Progresso é bastante usual a 
prática de "corte-queima" da vegetação, principalmente em localidades onde predomina a pecuária e a agricultura. Apesar desta prática ser apontada como uma atividade que resulta em consideráveis reduções da sustentabilidade, devido as diversas repetições dos ciclos de queima e consequentemente a redução no tempo de pousio da área (ANDRADE et al., 2014).

Considerando este contexto o trabalho teve como objetivo geral caracterizar as principais técnicas utilizadas para o uso do fogo na prática agrícola e a prevenção de queima controlada por agricultores familiares do município de Novo Progresso.

O Projeto de Desenvolvimento Sustentável (PDS) Terra Nossa, foi criado no ano de 2006 (Portaria/Incra N.3 de 06 de junho de 2006), nas Glebas Curuá e Gorotire, com a previsão inicialmente de assentamento de 1.000 unidades agrícolas familiares em um total de 149.842,5 ha. Posteriormente os limites foram alterados (retificação Diário Oficial da União no dia 13 de março de 2015) restabelecendo a área do PDS para 20.081 ha com a previsão de 373 unidades familiares beneficiárias. 0 assentamento está localizado as margens da Rodovia BR 163, a cerca de $90 \mathrm{~km}$ da sede municipal de Novo Progresso (Figura 1).

Devido uma parte do assentamento ter sido criado em áreas que anteriormente abrigavam fazendas, as áreas de uso alternativo destinadas aos agricultores assentados contém em grande parte de sua extensão área de pastagem e área de Preservação Permanente (APP) degradadas. Para atuar na recuperação destas, houve a implantação no assentamento do Projeto Horizonte Verde (PHV), iniciativa do Instituto Socioambiental Floranativa, abrangendo agricultores do PDS Terra Nossa com o objetivo de implantar sistemas agroflorestais.

Das 373 famílias previstas para serem beneficiadas com lotes rurais no PDS, apenas 161 famílias praticam alguma atividade agrícola ou possuem residência no assentamento (Novo Progresso, 2015). Deste total 44 famílias, demostraram interesse em participar da implementação de 
sistemas agroflorestais, em áreas já cultivadas ou sob condição de pousio, através do financiamento para reconversão produtiva de áreas promovido pelo PHV.

Assim, para a coleta de dados deste trabalho foram selecionados aleatoriamente 22 produtores cadastrados, abrangendo 50\% dos produtores envolvidos no projeto. 0 levantamento de informações baseouse na aplicação de questionário, através de entrevista semiestruturada no mês de fevereiro de 2015, em forma de entrevista pessoal, com caráter qualitativo e quantitativo. Em trabalhos deste caráter é comum uso desta metodologia para a entrevista de campo para a coleta e análise de dados conforme ressalta Andrade et al. (2014).

Figura 1. Mapa de localização das propriedades no PDS Terra Nossa em Novo Progresso.

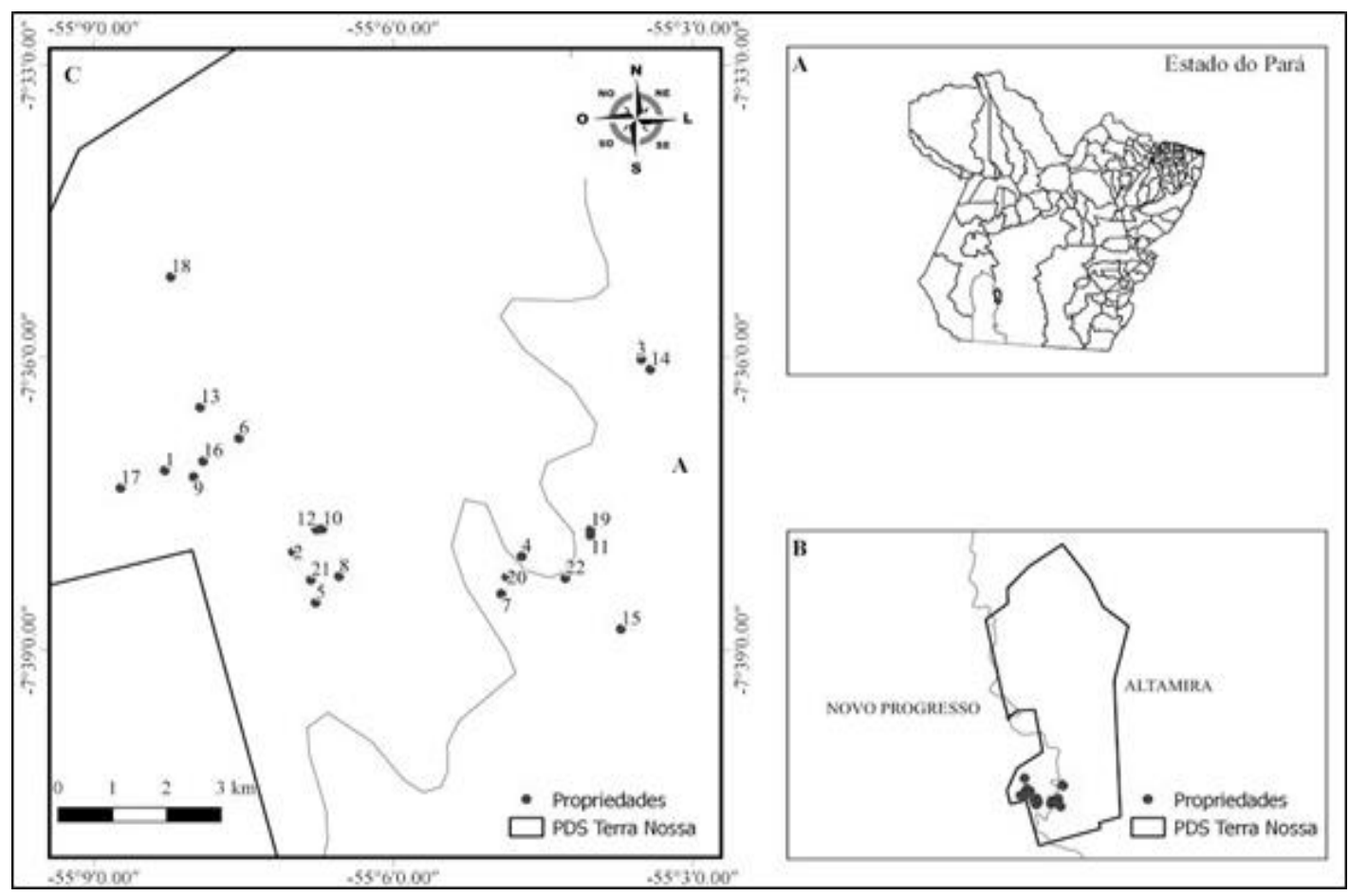


As principais informações pretendidas com as entrevistas foram identificar as técnicas de prevenção e combate a incêndios florestais utilizadas, a construção e utilização de aceiros, os tipos de queima que ocorrem na região e períodos mais frequentes, o uso do fogo e ocorrência de queima acidental, infraestrutura que foi prejudicada devido ao fogo e materiais e equipamentos utilizados na manutenção das áreas agrícolas. Os dados foram analisados e processados no Microsoft Excel 2010 aplicando-se estatística descritiva para obtenção de parâmetros para análise dos resultados.

$\mathrm{Na}$ região de Novo Progresso ocorrem muitos incêndios florestais, onde entendesse como incêndio florestal o fogo não controlado em floresta ou qualquer outra forma de vegetação, segundo o parágrafo único da Instrução Normativa IN - N. 51 publicada em 2010. (SEMAS, 2010).

Em época de seca a ocorrência de incêndios florestais na região é muito frequente, e nos lotes em que o PDS
Terra Nossa está localizado ainda é muito marcante a prática do uso do fogo nos lotes, o que sobrevém no fato de que a maioria das propriedades já sofreram danos oriundos de fogo acidental, onde se destaca o que afirmou Vasconcelos et al. (2005), no sul do Amazonas, pelo aumento da suscetibilidade da vegetação ao fogo causados pela longa estiagem. Deste modo, foi possível constatar que a maioria das propriedades avaliadas (90\%) no assentamento já sofreram com a invasão do fogo vindo de propriedades e/ou fazendas vizinhas, que não são limítrofes do local onde a propagação ocorreu mas sim, atingidas por fagulhas dispersas pelo vento. Ao mesmo tempo foi observado que em virtude da existência de áreas contínuas de pastagem entre as propriedades, uma queima sem controle poderá avançar diversos quilômetros, seguindo a direção predominante do vento, atingindo assim diversas propriedades ao longo de dias. 
Segundo Gontijo et al. (2011) todos esses fatores geram grandes perdas econômicas e ambientais.

Para o manejo das áreas do PDS Terra Nossa verificou-se que 14\% dos entrevistados não fazem o uso do fogo, enquanto que a grande maioria dos produtores (86\%), fazem uso do fogo para o controle de gramíneas forrageiras, fato comum nas propriedades haja visto que as terras dos lotes são procedentes de grandes fazendas. Neste sentido, o artigo $1^{\circ} \mathrm{da}$ IN - N.51 (SEMAS,2010) dispõe que é permitido o emprego do fogo em práticas agropastoris e florestais, mediante a queima controlada, precedida de autorização pelo órgão competente.

Esta prática é amplamente utilizada para o manejo e a renovação de pastagens apesar do impacto gerado sobre a diversidade de fauna e nutrição do solo como ressalta Gontijo et al. (2011). Se levar em consideração o ponto de vista energético e econômico, as queimadas são desnecessárias, uma que durante sua prática ocorre um grande desperdício de energia, além de que acarreta empobrecimento do solo, gerando uma maior necessidade de adubação química (FEARNSIDE, 2006).

Para Costa (2011) uma outra razão para a adoção desse procedimento está no fato dos agricultores acreditarem que o fogo traz benefícios para a área, como controle de plantas invasoras e disponibilidade imediata de nutrientes, o que pode ser observado nas entrevistas aos agricultores pela finalidade a qual apontaram a utilização do fogo, como queima de pastagem, juquira, resíduos enleirados e limpeza da área para a implantação do cultivo ou Sistema Agroflorestal. Esta prática é utilizada principalmente devido à escassez de maquinário que poderia ser utilizado para essa manutenção e trituração dos resíduos vegetais para renovação da área para novos cultivos.

Na área onde o PDS Terra Nossa está localizado, é marcante a prática do uso do fogo, pois a maioria das propriedades já sofreram com danos 
advindos do fogo acidental, principalmente em razão de origens externas aos limites do lote do produtor. Essas ocorrências podem gerar grandes perdas econômicas, paisagísticas, sociais e ambientais (GONTIJO et al., 2011).

Aos assentados são assistidos pela brigada de incêndios do Prevfogo instalada temporariamente na região para realização de palestras de prevenção e combate a incêndios florestais em áreas federais no município de Novo Progresso. Das 22 famílias entrevistadas 77\% participaram das palestras da brigada, 18\% nunca foram em alguma atividade oferecida pela brigada e 5\% não sabiam informar. O mesmo se reflete quanto a avaliação dos mesmos com relação a brigada, onde para $77 \%$ dos entrevistados as palestras foram bem aproveitáveis, enquanto que para 18\% não houve nenhum tipo de aproveitamento vindo das orientações da brigada.

Como medida de proteção ao fogo acidental, 95\% dos produtores entrevistados fazem o uso de aceiro (remoção da vegetação) em torno do local de cultivo, enquanto que apenas 5\% não adotam essa prática. Conforme disposto no Art. $4^{\circ}$ da IN - N.51(SEMAS, 2010), relacionado à operação de emprego do fogo, o interessado deverá fazer uso do aceiro para a obtenção de autorização para Queima Controlada.

Conforme observado no PDS Terra Nossa, os aceiros variavam em largura de 2 metros a 5,7 metros, variando de acordo com o tamanho da área destinada ao plantio. Segundo a IN N.51 deve-se preparar aceiros de no mínimo seis metros de largura, ampliando esta faixa quando as condições ambientais, topográficas, climáticas e o material combustível o determinarem, e/ou o aceiro deverá ter sua largura de no mínimo oito metros quando se destinar à proteção de áreas de florestas e de vegetação natural, de preservação permanente, de reserva legal, de unidades de conservação, aquelas especialmente protegidas em 
ato do poder público e de imóveis confrontantes pertencentes a terceiros.

Para a limpeza das áreas e sua manutenção, os agricultores fazem uso de algumas ferramentas em seus lotes, sendo elas manuais como rastelo, foice, terçado, enxada, e mecanizadas como roçadeira e trator, sendo que em $70 \%$ dos lotes se empregam ferramentas manuais para a manutenção da área, 25\% utilizam ferramentas mecanizadas para realizar suas manutenções nas áreas de cultivo. Apenas 1 (5\%) produtor possui seu próprio trator, o qual é alugado para os produtores que tiverem condições para pagar a hora/máquina, sendo que a grande maioria 19 (86\%) dispõem apenas das ferramentas manuais necessárias para a limpeza da área e apenas 2 (9\%) dos 22 entrevistados relataram possuir roçadeira costal própria, à qual é utilizada também como ferramenta de troca de diárias.

Para Santos et al. (2015) a infraestrutura é um fator determinante para utilização de ferramentas nos lotes, haja vista que muitos produtores não possuem condições para pagar a hora/máquina, além de que as condições da estrada que dá acesso aos lotes é muito precária, determinando assim um maior uso de ferramentas manuais na manutenção dos lotes, salientando-se como um grande desafio enfrentado pelos agricultores familiares.

Com relação a brigada de incêndios da região, dos 22 entrevistados 64\% relataram ter obtido o apoio da brigada e consequentemente facilidade no agendamento dos serviços da mesma, enquanto que para 32\% não houve essa facilidade de agendamento e nem o apoio da mesma, e para 5\% não foi possível obter dados com relação a este questionamento. Porém, quando perguntados quanto a atuação da brigada, $\quad 45 \%$ dos entrevistados relataram que os mesmos auxiliaram na hora da queima, enquanto que 50\% afirmaram que não tiveram esse auxilio. Contudo, estes fatos não afetaram diretamente o processo de queima nos lotes, haja vista que não se obteve 
relatos de escape do fogo para além das áreas a serem queimadas. Segundo Moreira e Carmo (2004) é necessária uma adoção mais firme de políticas públicas no meio rural, que venham a contribuir para o seu melhor desenvolvimento.

O aceiro é uma medida preventiva utilizada pelos agricultores para proteger as áreas circundantes ao local de queima, evitar o escape do fogo na hora da queima ou até mesmo proteger os lotes contrafogo invasor oriundos ou não de propriedades próximas. Conforme foi observado na pesquisa realizada por Santos et al. (2015) a importância desta técnica como medida preventiva, onde na área de estudo o fogo acidental se deu em função de causas externas, em que alguns lotes foram afetados pela invasão de fogo oriundo de áreas limítrofes e/ou foram atingidos por fogo proveniente de áreas não limítrofes através da propagação por fagulhas dispersas pelo vento.

Quanto à manutenção dos aceiros, 9\% dos entrevistados fazem manutenção com maquinário, 45\% fazem a manutenção do aceiro manualmente e os outros $45 \%$ não fazem nenhum tipo de manutenção, o que acaba muitas das vezes ocasionando perda de controle na hora da queima, causando fogo acidental no lote e demais propriedades. Para Santos et al. (2015) esses fatos demonstram a dependência e vulnerabilidade para a realização das atividades cotidianas nos lotes, sendo estes fatores imprescindíveis para a autonomia dos agricultores familiares, e dependem da presença e ação de órgãos públicos junto aos agricultores familiares.

A maioria dos agricultores utilizam o aceiro em seus lotes, tanto como medida de proteção a área cultivada, como pré-requisito de autorização a queima controlada e mesmo não estando nas dimensões previstas legalmente têm demonstrado uma grande eficiência na sua utilização.

As técnicas de prevenção a incêndios adotadas no PDS Terra Nossa d, apesar de não estarem 
totalmente de acordo com a legislação brasileira, demonstraram ser eficientes no controle do fogo, haja vista que os lotes dos produtores rurais não foram afetados pela queima controlada, e sim por incêndios oriundos de propriedades limítrofes que não adotaram praticas preventivas aos incêndios.

\section{REFERÊNCIAS}

ANDRADE, J. P.; SOUSA, F. F.; KATO, O. R.; ALMEIDA, R. H. C.; SOUZA, A. M.; NEVES, J. L. G. de S. Agricultura de "corte e trituração" e implementação de sistema agroflorestal: Uma experiência de transição agroecológica no nordeste paraense. Cadernos de Agroecologia, [S.I.], v. 9, n. 4, fev. 2015. ISSN 2236-7934. Disponível em: <http://aba-

agroecologia.org.br/revistas/index.php /cad/article/view/16699>. Acesso em: 08 out. 2017.

COSTA, M. R. G. F.; CANDIDO, M. J. D.; CARNEIRO, M. S. de S.; MORAIS NETO, L. B. de; MAGALHAES, J. A.; COSTA, N. de L. Uso do Fogo em Pastagens Naturais. PUBVET, Londrina, V. 5, N. 9, Ed. 156, Art. 1050, 2011. Disponível em:< https://www.embrapa.br/busca-depublicacoes/-/publicacao/888856/usodo-fogo-em-pastagens-naturais $>$. Acesso em: 08 out. 2017.
COSTA, Y. T.; RODRIGUES, S. C. Efeito Do Fogo Sobre Vegetação E Solo A Partir De Estudo Experimental Em Ambiente De Cerrado. Revista do Departamento de Geografia - USP, Volume 30 (2015), p. 149 a 165. Disponivel em: <http://dx.doi.org/10.11606/rdg.v30i0.1 01686 > . Acesso em: 08 out. 2017.

DICK, D. P.; MARTINAZZO, R.; DALMOLIN, R. S. D.; JACQUES, A. V. Á.; MIELNICZUK, J.; ROSA, A. S. Impacto da queima nos atributos químicos e na composição química da matéria orgânica do solo e na vegetação.

Pesquisa Agropecuária Brasileira [online]. 2008, vol.43, n.5, pp.633-640. ISSN 0100-204X. Disponível em:< http://dx.doi.org/10.1590/S0100-

204X2008000500011>. Acesso em: 08 out. 2017.

FEARNSIDE, P. M. Desmatamento na Amazônia: dinâmica, impactos e controle. Acta Amazonica [online]. 2006, vol.36, n.3, pp.395-400. ISSN 0044-5967. Disponível em: <http://dx.doi.org/10.1590/S004459672006000300018>. Acesso em: 08 out. 2017.

GONTIJO, G. A. B.; PEREIRA, A. A.; OLIVEIRA, E. D. S. de; ACERBI JÚNIOR, F. W. Detecção de queimadas e validação de focos de calor utilizando produtos de Sensoriamento Remoto. Anais XV Simpósio Brasileiro de Sensoriamento Remoto - SBSR, Curitiba, PR, Brasil, 30 de abril a 05 de maio de 2011, INPE p.7966. Disponível em: 
http://www.dsr.inpe.br/sbsr2011/files/p 1587.pdf>. Acesso em: 08 out. 2017.

IBAMA - INSTITUTO BRASILEIRO DO MEIO AMBIENTE E DOS RECURSOS NATURAIS RENOVÁVEIS. Dispõe sobre a necessidade de regulamentar a sistemática de queima controlada. Portaria no 94-N, de 09 de Julho de 1998. Brasília, v. 2. p. 367, 2006. Disponível em:

http://ibama.gov.br/phocadownload/p revfogo/legislacao/portaria_ibama_94_ n_98.pdf>. Acesso em: 08 out. 2017.

INCRA - INSTITUTO NACIONAL DE COLONIZAÇÃO E REFORMA AGRÁRIA. Base de dados da agricultura familiar (SADE). Convênio FAO/Incra. Disponível em: $<$ http://www.incra.gov.br/fao/default.h tm> Acesso em: 08 out. 2017.

IPEA - INSTITUTO DE PESQUISA APLICADA. Relatório de Pesquisa: Caracterização e Análise da Dinâmica da Produção Agropecuária na Amazônia Brasileira Uma análise a partir do Censo Agropecuário 2006. Brasília, 2013. Disponível em: < http://www.ipea.gov.br/agencia/image s/stories/PDFs/relatoriopesquisa/13031 9_relatorio_caracterizacao_analise.pdf

>. Acesso em: 08 out. 2017.

LIESENFELD, M. V. de A.; VIEIRA, G.; MIRANDA, I. P. de A. Ecologia do fogo e o impacto na vegetação da Amazônia. Pesquisa Florestal Brasileira. Brazilian Journal of Forestry Research. ISSN: 1983-2605, Colombo, v. 36, n. 88, p. 505-517, out./dez. 2016 (online). Disponível
$<$ http://pfb.cnpf.embrapa.br/pfb/> Acesso em: 08 out.2017.

MARSCHNER, W:; VANDERLINDE, T. As práticas dos movimentos sociais no uso e nas relações com a terra e o meio ambiente - o caso do capa e da assesoar. Revista de geografia agrária, v. 10, n. 21, p. 59-88, ago., 2015. Disponível em: http://www.seer.ufu.br/index.php/cam poterritorio/article/view/28853>.

Acesso em: 08 out. 2017.

MOREIRA, R. M.; CARMO, M. S. Agroecologia na construção do desenvolvimento rural sustentável. Agricultura. São Paulo, São Paulo, v. 51, n. 2, p. 37-56, jul./dez. 2004. Disponível em:

<http://www.agriculturasamazonicas.u fpa.br/PDF'S/artigo\%20Moreira\%20e\% 20Carmo\%20Agroecologia.pdf>.

Acesso em: 08 out. 2017.

OLIVEIRA, D. dos S. de; BATISTA, A. C.; Soares, R. V.; GRODZKI, L.; VOSGERAU, J. Zoneamento de risco de incêndios florestais para o estado do paraná. FLORESTA 34 (2), Mai/Ago, 2004, 217 221, Curitiba, Pr.

PEDROSO JUNIOR, N. N.; MURRIETA, R. S. S.; ADAMS, C. A agricultura de corte e queima: um sistema em transformação. Bol. Mus. Para. Emílio Goeldi. Ciênc. hum. [online]. 2008, vol.3, n.2, pp.153-174. ISSN 19818122. Disponível em: <http://dx.doi.org/10.1590/S1981$81222008000200003>$. Acesso em: 08 out. 2017. 
SÁ, T. D. de A.; KATO, O. R.; VASCONCELOS, S. S.; SHIMIZU, M.; ARAGÃO, D. V.; AZEVEDO, C. M. B. C. de; BORGES, A. C. M. R.; SILVA, A. R. B. e. Alternativas à agricultura de corte e queima em processos de transição agroecológica: um desafio para a agricultura amazónica. In: Congresso Latinoamericano de Agroceologia, 5. 2015, La Plata. Archivo Digital: descarga $y$ online ISBN 978-950-34-1265-7. Disponível em: < http://ainfo.cnptia.embrapa.br/digital/ bitstream/item/136468/1/A1-258.pdf>. Acesso em: 08 out. 2017.

SANTOS, J. A. C. dOS; PAULETTO, D.; NASCIMENTO, G. de C. dos S. N.; SILVA, S. U. P. da; MOTA, C. G. Desafios para a produção da agricultura familiar no PDS Terra Nossa, município de Novo Progresso, Pará. Cadernos de Agroecologia, [S.I.], v. 10, n. 3, maio 2016. ISSN 2236-7934. Disponível em: <http://aba-

agroecologia.org.br/revistas/index.php /cad/article/view/19705>. Acesso em: 13 nov. 2017.

SEMAS. IN - INSTRUÇÃO NORMATIVA N.51, de 08 de setembro de 2010. Dispõe sobre a Autorização de Queima Controlada no âmbito do Estado do Pará e da outras providencias. Belém, $2010 . \quad$ Disponível em: $<$ https://www.semas.pa.gov.br/2010/0 9/08/10976/> . Acesso em: 08 out. 2017.

SOARES, R. V.; BATISTA, A. C. Incêndios florestais: controle, efeitos e uso do fogo. Curitiba, 2007. 264p. :il.
VASCONCELOS, S. S. de; FEARNSIDE, P. M.; GRAÇA, P. M. L. de A.; SILVA, P. R. T. da; DIAS, D. V. Suscetibilidade da vegetação ao fogo no sul do amazonas sob condições meteorológicas atípicas durante a seca de 2005. Revista Brasileira de Meteorologia, v.30, n.2, 134 - 144, 2015. Disponível em: <http://dx.doi.org/10.1590/0102778620140070>. Acesso em: 08 out. 2017. 